\title{
Transplantation of an allogeneic bone graft in treatment of post-sternotomy massive bone loss defects
}

\author{
Martin Kaláb ${ }^{1 *}$, Jan Karkoška ${ }^{2}$, Milan Kamínek ${ }^{3}$, Eva Matějková², Vladimír Lonský1 \\ From World Society of Cardiothoracic Surgeons 25th Anniversary Congress, Edinburgh \\ Edinburgh, UK. 19-22 September 2015
}

\section{Background/Introduction}

Severe post-sternotomy dehiscence resulting in sternum and ribs losses, represent a surgical issue with mortality risk of $40 \%$. Chest instability causes respiratory insufficiency, obstruction in disconnection from mechanical pulmonary ventilation and other soft tissue healing complications. Extensive bone tissue loss hinders the use of AO osteosynthesis.

\section{Aims/Objectives}

Basing on orthopedic experience in bone defects replacement, we developed a technique of chest wall reconstruction using an allogeneic bone graft.

\section{Method}

In the period 2011-2014, we performed allogeneic bone graft transplantation in 10 patients with extensive poststernotomy defect of the chest wall. In 9 cases we used sternal graft, while in 1 case calva bone graft was used. Prior to the transplant, each patient underwent vacuum assisted closure treatment of the wound and general antibiotic therapy. Thorax and the graft stabilization was performed using transversal titanium plates with bicortical screws. In accordance with valid legislation, bone allograft was prepared by tissue centre. Powdered allogeneic spongy bone was used to enhance contact of graft and edges of sternal bone. In 9 cases the closure of soft tissues was performed using direct suture of mobilized pectoral flaps, while in 1 case $\mathrm{V}-\mathrm{Y}$ transposition of pectoral flap was applied.

'Department of Cardiosurgery, University Hospital Olomouc and Faculty of Medicine, Palacky University Olomouc, I. P. Pavlova 6, Olomouc, 775 20, Czech Republic

Full list of author information is available at the end of the article

\section{Results}

In 6 cases (60\%) the reconstructed chest wall was successfully healed without further complications. In 3 cases (30\%) additional resuture of soft tissues and skin in the wound lower part was performed during hospitalization. Nevertheless, a high stability of the chest wall with respiratory insufficiency improvement and a very good final cosmetic effect of the wound was achieved in these cases. Healing wasn't sufficient in 1 case (10\%). Average length of the follow-up process of all the patients was 14.1 months (1-36). In four cooperating patients a scintigraphy examination of the chest wall was performed and it proved high healing activity of the graft and spongy bone.

\section{Discussion/Conclusion}

Based on our existing experience, the transplantation of allogeneic bone graft seems to represent a promising method of management of severe sternal dehiscence. The procedure is easy to apply, with favourable functional and cosmetic effect.

\section{Authors' details}

'Department of Cardiosurgery, University Hospital Olomouc and Faculty of Medicine, Palacky University Olomouc, I. P. Pavlova 6, Olomouc, 775 20, Czech Republic. ${ }^{2}$ National Cell and Tissue Centre, Palachovo náměstí 726/2, Brno, 62500 Czech Republic. ${ }^{3}$ Department of Nuclear Medicine, University Hospital Olomouc and Faculty of Medicine, Palacky University Olomouc, I. P. Pavlova 6, Olomouc, 775 20, Czech Republic.

Published: 16 December 2015

doi:10.1186/1749-8090-10-S1-A130

Cite this article as: Kaláb et al:: Transplantation of an allogeneic bone graft in treatment of post-sternotomy massive bone loss defects. Journal of Cardiothoracic Surgery 2015 10(Suppl 1):A130. 